\title{
TMT Cognitive Capability and Organizational Outcomes: A Theoretical Review
}

\author{
Nicodemus M. Mutinda ${ }^{1} \&$ James M. Kilika $^{2}$ \\ ${ }^{1}$ Researcher, Kenya Industrial Research and Development Institute (KIRDI), Kenya \\ ${ }^{2}$ Department of Business Administration, Kenyatta University, Kenya \\ Correspondence: James M. Kilika, Department of Business Administration, Kenyatta University, Kenya.
}

\author{
Received: April 22, 2019 \\ Accepted: July 1, 2019 \\ Online Published: July 18, 2019 \\ doi:10.5539/ibr.v12n8p31 \\ URL: https://doi.org/10.5539/ibr.v12n8p31
}

\begin{abstract}
Extant strategic management literature has followed two divergent paradigms. One is based on the tenets of industrial organization theory and argues that strategic decision making and action is purely a chance affair because the industry environment determines whether an organizational will survive or not and that the decisions and actions of the organizational players have no role at all. The second paradigm is based on the Resources Based View (RBV) and argues that organizational strategic choice and action is purely a resources, capability and competence deployment affair. Even though recent scholarship in strategic management has attempted to integrate the two paradigms to explain organizational strategic decision making and outcome, it is however yet to put forward a theoretical model explaining how the two paradigms integrate. In this paper, the authors bring on board a managerial cognitive capability perspective to play the role of a catalyst that blends the two paradigms together in explaining organizational outcomes. The paper reviews extant conceptual, theoretical and empirical literature and builds a case for a theoretical model linking TMT cognitive capability and organizational outcomes in the context of both industry environment dynamics and internal organization dynamics. The study identifies key organization outcomes resulting from the deployment of TMT cognitive capability as strategic choice, strategic flexibility and organizational performance while the key contextual factor that condition the outcomes include industry velocity and organizational characteristics. Based on the postulates of several underpinning theories, the paper identifies a phenomenon arising from deployment of TMT Cognitive Capability in the context of dynamic business environments and proposes a theoretical model that raises several implications for future empirical work.
\end{abstract}

Keywords: cognition, firm characteristics, industry velocity, managerial cognitive capability, organizational performance, strategic flexibility and top management team

\section{Introduction}

A dominant normative philosophy underpinning strategic management has focused on generating insights into how, when, and why some firms outperform others in the short run and sustain their superior performance in the long run (Najmaei \& Sadeghinejad, 2016). It has been based on Industrial Organization (IO) theory which takes a deterministic approach in strategic management by holding that the strategic choices made by a firm are a reflection of the firm's industry structure (Nadkarni \& Barr, 2008). The Resource Based View (RBV) however shifted the attention from the industry structure to the organization resources and capabilities in an attempt to explain why some firms pursue particular strategies and not others (Barney, 1991). The application of the RBV in dynamic contexts led to the birth of the Dynamic Capability (DC) theory, which aimed at linking organizational characteristics with firm external environment (Teece, 2007).

Later researchers realized that managers play a key role in configuring resources and capabilities to drive firm performance and therefore began to investigate the role managers' play in strategic management. Teece (2007) identified managerial capability as the key form of dynamic capability that enables the firm to match its external environment changes with the internal capabilities and resources. However the major theoretical stream that has focused on managerial role in strategic management is the managerial cognition perspective. Indeed Eggers and Kaplan (2009) posited that managerial capability is largely dependent on managerial cognition, which was also supported by Helfat and Peteraf, (2015), who coined the term managerial cognitive capability as the triad ability of a firm namely; environment scanning, opportunity or threat identification and appropriate response action framing. 
The role of managerial cognitive capability in explaining organization's strategic outcome is also supported by the Upper Echelon theorem which posits that a firm's strategic outcomes are largely dependent on the decisions made by its Top Management Team (TMT) and that the executives' decisions are influenced by their cognitive capacities (Hambrick, 2007). However most often top managers due to their cognitive diversity hold on different strategic choices (Beach \& Connolly, 2005; Yan \& Chew, 2011). On the one hand, TMT cognitive diversity can cause group affective conflicts that will hinder strategic consensus and actions and thus negatively affecting the firm performance. While on the other hand when the TMT is acting in harmony, their cognitive diversity means a wider overall cognitive base which translates to better strategic choices (Gavetti, 2012).

Managerial cognitive capabilities are especially crucial in rapidly changing environments that require constant monitoring and adapting to new environmental conditions. In relatively stable business environment, managers constantly face similar environmental aspects, and thus the effects of managerial cognition on organizational outcomes in such environment is low. However in highly dynamic business environments, managerial cognition effects on firms strategic choices is high and its more reflected in firm's strategic outcomes (Abrahamson \& Hambrick, 1997; Hambrick \& Finkelstein, 1987).

Although research in managerial cognition has been ongoing for over two decades (Kaplan 2011), it is still not clear on how it relates to organizational outcomes. The cause-effect logical explanation in managerial cognition-organizational outcomes relationship is still unclear. In fact cognitions-performance studies have yielded mixed results, some indicating significant positive relationship while others posting insignificant relationships (Helfat \& Peteraf, 2015). Managerial cognition literature has also focused more on cognitive biases and less on cognitive abilities. Most of the existing studies have concluded that what matters for strategic actions is the managers' belief about the business environment and not the reality of the environment (Nadkarni \& Barr, 2008). This means that, the success of strategic decisions and actions is left to chance because it will only happen when the decision makers' subjective mental models of the particular environmental event matches with the objective environmental reality. The focus on subjective managerial cognitive representations takes strategy discussion back to the deterministic arguments that it is the environment only that determines success of strategies but not managers actions. In view of this logic, scholarship in strategic management needs to reconcile the contradictions so as to sustain the gains so far made in the stream of literature focusing on RBV in line with findings made by earlier studies by Meyer, Estrin, Bhaumik \& Peng (2009) and Kilika, (2012).

\subsection{Statement of the Problem}

Even though TMT has been given much attention in the strategic management literature, it is observed from this rich repository that some of its ingredients that enable TMTs to offer their contribution to organizations have been ignored. Extant literature on TMT has given much attention to TMT demographic factors and ignored TMT psychological attributes (Hambrick, 2007; Eggers \& Kaplan, 2009; Kaplan, 2011; Helfat \& Peteraf, 2015). Most studies in upper echelons have focused on observable characteristics including age, education level, gender, experience and tenure to understand decision making process by executives (Hambrick \& Mason, 1984; Chen, Lin, \& Michel, 2010). Hambrick (2007) acknowledged that demographic characteristics do not provide a clear link to the psychological dimensions they are meant to represent. According to Hambrick (2007) there are rare cases in which scholars have attempted to move beyond these objective characteristics (demographic characteristics) to measure cognition. Also the pieces of scholarly literature focusing on capabilities in general and specifically on dynamic capabilities have not considered this potential and given it serious scholarly attention. Recent literature however is pointing at potential contribution of the TMT psychological attributes especially those touching on their cognitive capabilities to organizational outcomes (Helfat \& Peteraf, 2015). The authors cite this as an important call for scholarship to explore the nature of the construct of TMT cognitive capability with a view to demonstrating its potential for enhancing the quality of the contribution of TMTs in organizations.

In responding to the above limitations in TMT cognitions and organizational outcomes literature the authors call for scholarship to create an understanding regarding, first the nature of the components of the TMT cognitive capability, secondly the outcomes of its deployment and thirdly the internal and external organizational contexts likely to constrain or facilitate its deployment in organizations. With regard to the need to understand the nature of the components of the TMT cognitive capability, we note that the construct by its nature requires an integrated approach to consolidate a multidisciplinary based literature that ranges from but not limited to psychology, strategic management and the behavioural sciences (Kaplan, 2011). This effort is meant to consider the very nature of the construct that upon deployment in organizational systems as a form of strategic resource stands to deliver benefits of strategic importance to organizations so that its strategic role in line with the basic expectations of the contribution of TMTs will be realized through sustained superior firm performance. 
Secondly, if TMT cognitive capability is conceived from the standpoint of RBV theory as a strategic resource, then its deployment into the systems of an organization raises implications on the outcomes it is likely to confer to the organization. The focus on strategic management largely is on those outcomes so as to explain how such an asset influences the key goals of management regarding competitiveness and sustained performance. Based on this reasoning, the authors cite this as an important call for scholarship to consider TMT cognitive capability with a view to understanding its outcomes that are of interest to the strategic goals of firms. Alongside this reasoning, it is also important to consider TMT cognitive capability in the context of the reality of the organizational context that requires a strategic thinking lens. With this kind of reasoning, we point out that two factors are of relevance, namely the characteristics of the organization within which TMTs offer their contribution to steer firms forward and the external context for business that not only sets the demands to be satisfied but also sets the agenda for TMTs to consider in playing their strategic roles in their organizations. The point of interest is to create an understanding of how the very nature and posture of the two can act in a manner that will facilitate or constrain the functioning of TMTs in their attempt to deliver desired benefits for their organizations (Adner \& Helfat, 2003).

In view of these considerations, this paper undertook to explore how the TMT cognitive capability affects organizational outcomes. Specifically the paper sought to first review extant theoretical, conceptual and empirical literature on the TMT cognitive capability components, secondly to identify the effects of the TMT cognitive capability deployment in dynamic business environments and finally to propose a suitable theoretical framework that describes the phenomenon.

The current paper contributes to the existing literature in several ways. First the paper responds to the existing gap in the understanding of TMT cognitive capability and its outcomes (Helfat \& Peteraf, 2015), which in our view stands better explained upon identification of the key components of TMT cognitive capability. By application of a multidisciplinary based set of literature, the paper consolidates diverse pieces of knowledge to propose several components of the construct of TMT capability.

Secondly, the phenomenon brought about by TMT cognitive capability is something of interest to strategic thinkers and managers alike (Moldoveanu, 2009). In this paper, we explore the phenomenon to demonstrate how it is constructed as well as how it stands to interact with the reality of the contexts that TMTs find themselves making decisions to steer their firms forward. Lastly, the paper documents the phenomenon through a proposed theoretical framework. We observe that such a move stands to not only benefit scholarship through conceptualization and future empirical work but also the field of practice that stands a better position of understanding the constructs in the phenomenon and their operational indicators.

\section{Conceptualization of Key Constructs}

\subsection{TMT Cognitive Capability}

Cognition refers to mental activities relating to information search, storage, retrieval, and processing (Armstrong \& Hird, 2009). It also encompasses mental models and mental processes that operate on those models (Thagard, 1996) as well as emotions, intuition and value judgment (Noteboom, 2009). Cognition is partly inborn and partly constructed by experience along life trajectories (Armstrong, Cools, \& Sadler-Smith, 2012; Noteboom, 2009). Therefore, differences in life trajectories, lead to differences in managers mental models and mental information processing capacities (Noteboom, 2009; Armstrong, Cools, \& Sadler-Smith, 2012).

Managerial cognitive capability is the mental representation and mental processing ability that a manager uses to notice, interpret and act on an environmental stimuli (Helfat \& Peteraf, 2015). Extant literature has denoted mental representation and mental processing by different terminologies such as knowledge structures, cognitive maps, mental models, frames, schema, schemata, or interpretive schemes (Ocasio, 2011). Mental processes and mental representations significantly influence the managers' cognitive capabilities and consequently the quality of subsequent strategic choices and actions (Narayanan, Zane, \& Kemmerer, 2011). Managers' interpretation of environmental events determines how they respond to those environmental events and their interpretation of the environmental events is dependent on their mental structures and mental processes (Ocasio, 1997). Managerial cognitive capability therefore affects strategic choices and actions because the meaning managers' give to environmental events determine the managers' decisions (Gavetti \& Warglien, 2015) and those meaning are affected by the managers' information recognition, interpretation, and actions abilities (Daft \& Weick, 1984; Ocasio, 1997).

The managerial cognitive capability concept is drawn from the Upper Echelon perspective which posits that the decisions made by a firm's top executives affects its strategic choices, actions and outcomes and that the executives' decisions are influenced by their cognitive capabilities (Hambrick, 2007). This means that the ability 
to notice and respond to changes in the business environment is determined by the top managers' cognitive processes (Nadkarni \& Barr, 2008). Therefore one can deduce that organizational adaptation to environmental changes is depended on TMT cognitive capability.

Helfat and Peteraf (2015), identified key managerial cognitive capabilities to include; perception, attention, reasoning and communication. Perception is the mental ability to receive, filter, recognize and interpret an environmental stimuli. This ability is dependent on prior knowledge, expectation, belief and experience. During the perception process the human mind combines information from the received and filtered stimuli with existing knowledge and beliefs, to interpret the properties of the environment stimuli (NAHMC, 1996; American Psychological Association, 2009; Helfat \& Peteraf, 2015; Powell, Lovallo, \& Caringal, 2006). Perception affects the ability to recognize opportunities and threats arising from an environmental event by recognizing, analyzing and interpreting the cause-effect patterns of the environmental event. The faster the ability to recognize and interpret the environmental patterns determines the faster a firm will recognize emerging business opportunities and threats which will in turn enable the firm to take the necessary respond action and benefit from first mover advantages (Baron, 2006; Lieberman \& Montgomery, 1988).

Attention is the selection of a set of information from the environmental event for analysis and interpretation (American Psychological Association, 2009; Kosslyn \& Rosenberg, 2006). Attention involves deploying the mental sensory glands to receive stimuli from environmental events, detecting environmental stimuli and storage of the stimuli information in the brain (Posner \& Petersen, 1990; Weber \& Johnson, 2009). The more the mind is exposed to certain environmental stimuli the faster and effective the mind will be able to attend to similar environmental stimuli in the future (Rueda, Posner \& Rothbart, 2005). Dynamic business environment calls for high attention capacity to support environmental scanning and identification of opportunities and threats.

TMT attention capability is crucial in strategic decision making because it determines the extent to which an environmental event in considered as a factor in the firm's strategic choices, actions and outcomes ((Weick, 1995; Nadkarni \& Barr, 2008). Dynamic business environments require high TMT attention capacity to cope with discontinuous changes (Eggers \& Kaplan, 2009; Cho \& Hambrick, 2006; Tuggle, Schnatterly, \& Johnson, 2010).

Reasoning is mental activity that applies logic in solving problems (Colman, 2006). It determines the ability to evaluate information emanating from an environmental event without relying on prior experience (Stanovich, 2009; Kosslyn \& Rosenberg, 2006; Gazzaniga, Heatherton \& Halpern, 2010). Most often managers utilize heuristic processing in problem-solving rather than reasoning (Stanovich, 2009). Heuristic processing relies on short cuts rather than extensive analysis of multiple possibilities (Kosslyn \& Rosenberg, 2006). Managers who rely more on reasoning experienced less biases in decision-making as compared to those who rely on heuristics (Kahneman, 2011). Reasoning influences ones capacity to accurately interpret cause-effect relationships among environmental stimuli which in turn affects strategic decisions, actions and outcomes (Nadkarni \& Barr, 2008). Environmental stimuli only become relevant if top managers are able to link them to the organizational outcomes (Huff, 1990; Dutton, Fahey \& Narayanan, 1983).

Communication is passing verbal or non-verbal signals from one individual to other (s) describing an environmental event (Colman, 2006). Communication is a mental, physical, emotional process since one must think about what to communicate and how to communicate it effectively as well as get emotionally attached to the message and use physical means to pass or emphasize the message (Colman, 2006). Communication affects an individual's ability to understand others' opinion and the means to influence the thinking and actions of others (Helfat \& Peteraf, 2015). Managerial cognition is social constructed where one managers influences the cognitive ability of the other managers through social interactions.

From the above identified components of TMT cognitive capability one can link TMT cognitive capability to strategic choices, actions and outcomes (Gavetti, 2005; Kaplan \& Tripsa, 2008; Simon, 1991; Walsh, 1995). This can be explained by the understanding that the ability to align strategic choices and actions to environmental events is largely depended on the TMT ability to correctly understand the environmental events and frame the appropriate response actions (Tripsal \& Gavetti, 2000). The more the TMT is able to correctly understand the industry dynamics under which their firm operates the better are the strategic choices they make and the higher the firm's performance (Garry \& Wood, 2010). Correct understanding of the business environment must be backed up with a correct understanding of the link between the managers' response actions with expected firm's outcomes. Both the environmental understanding and action-outcome response require cognitive capability for information processing (Hodgkinson \& Healey, 2011).

Thus, in view of this complex setting in which TMTs have to make decisions, the deployment of TMT cognitive capability breeds into the organizational systems two forms of outcomes i.e. intermediate and ultimate. The 
intermediate involve both the capability unleashed into the system regarding the how and the nature of the decision making. The outcome regarding the how of the decision making corresponds to the climate created for enhancing the decisions making which in this case calls for strategic flexibility, while that regarding the nature of the decision corresponds to the strategic choice. Therefore the intermediate outcomes give rise to strategic flexibility and strategic choice. The ultimate outcome arises from the main point of focus of the deployment of TMT cognitive capabilities of enhancing the performance of the firm. Thus the second type of outcome from TMT cognitive capability is the firm performance.

In deploying the TMT cognitive capability to bring out the above indicated outcomes, an important observation arises from the fact that what is manifested is a strategic management phenomenon that needs to be aligned to the nature of strategic thinking. Critical component of strategic thinking is the ever changing business environment. We argue that, for the optimal deployment of the TMT cognitive capability, it would be important to understand the firm's defining characteristics that offer the posture for TMT cognitive capabilities deployment as well as the degree of the environmental dynamism that the TMTs are called upon to respond to. We rely on relevant knowledge drawn from previous work on organizations and managerial cognitions with regard to perception of the dynamics of the external environment (Child, 1972; Child, 1997; McCarthy, Lawrence, Wixted \& Gordon, 2010; Nadkarni \& Barr, 2008). Thus, alongside understanding the outcomes arising from deployment of TMT cognitive capability, we suggest a consideration of the organization's unique characteristics and the aspect of environmental dynamisms.

\subsection{Strategic Choice}

Strategic choice is the basis of organizational strategy and connects an organizational environment with its resources through its managers' actions (Child, 1972, 1997). Strategic decision making is a cognitive process that scans for information from the organizational environment, analyses the information and interprets it to make important organizational choices that in turn lead to certain organizational outcomes. It is difficult to completely and accurately comprehend the information about a particular environmental event and therefore strategic decision making is associated with risk and uncertainty. This explains why strategic decisions are regarded as the most important decisions in organizations. The high level of risk and uncertainty associate with strategic decisions directly influence firm's performance.

Strategic choices are usually the responsibility of top managers (Hambrick \& Mason, 1984) and there success is determined by the alignment of the TMT decisions and the realities of the external organizational environment coupled with the nature of the internal organizational dynamics put in place as a response to changes in the environmental events. Strategic decisions are also the most difficult ones in an organization because they are complex and difficult to reverse once made (Elbanna, 2006).

The critical aspects of strategic choices have been identified to be; comprehensiveness, quality, effectiveness, and speed. Choice comprehensiveness refers to the degree to which the environmental events features are scanned, analyzed and included in the strategic decisions as well as the extent to which all the strategic options are considered in the strategic decision making process (Fredrickson \& Mitchell,1984; Muithya \& Kilika, 2019). Quality of strategic choices is the degree to which the strategic choices have affected the performance of an organization (Amason, 1996). Strategic choice effectiveness is the extent to which a strategic choice results in desired outcomes (Dean \& Sharfman, 1996) while strategic choice speed is the pace of making and implementing a strategic choice (Eisenhardt, 1989). To improve a firm's performance, its TMT must strive to quickly and comprehensively make high-quality and effective strategic choices (Elbanna, 2006).

The success of strategic choices is depended on the alignment between the changes in the firm's external environment and actions taken to change the firm's internal environment in response to the changes. Today's turbulent business environment means an organisation cannot rely on the same strategic choices over and over again to maintain sustainable competitive advantage. Secondly, such business environment requires quick response actions and this calls for the organization to build dynamic capabilities. TMT cognitive capabilities have been linked to dynamic capabilities of opportunity sensing and seizing, resource configurations and deployment (Helfat \& Peteraf, 2015). Therefore one can deduce that TMT cognitive capability is an important precursor for strategic choice making.

\subsection{Strategic Flexibility}

Strategic flexibility is defined as the ability of a firm to quickly adjust its strategic goals and internal behaviour and actions in response to changes in the competitive business environment (Abbott \& Banerji, 2003; Shimizu \& Hitt, 2004; Hitt, Keats \& DeMarrie, 1998; Wright \& Snell, 1998; Escrig-Tena, Bou-Llusar, Beltr'an-Mart'in \& Roca-Puig, 2011; Nadkarni \& Herrmann, 2010; Roberts \& Stockport, 2009; Sanchez, 1997; Zhang, 2006; 
Tamayo-Torres, Ruiz-Moreno, \& Verd'u, 2010). Strategic flexibility is not only a function of the firm's ability to respond to its environmental changes, but also a function of the firm's ability to shape its business environment (Brozovic, 2018). Strategic flexibility is a crucial organizational behaviour necessary for the survival of firms in highly dynamic business environments (Combe, Rudd, Leeflang \& Greenley, 2012; Li, Liu \& Duan, 2008; Sanchez 1995). Strategic flexibility therefore enables firms operating in dynamic environments to obtain sustainable competitive advantage and ultimately sustainable performance by proactively responding to environmental opportunities and threats (Ussahawanitchakit \& Sriboonlue, 2011).

Extant literature identifies three dimensions of strategic flexibility; resource flexibility (Hai, 2014; Cingoz, 2013), strategic action flexibility (Cingoz, 2013; Nadkarni \& Narayanan, 2007) and coordination flexibility (Cingoz, 2013; Nadkarni \& Narayanan, 2007; Sanchez, 1995). Resource flexibility is the organizational capability to build a pool of resources with multiple uses or that can be easily switched between different strategic commitments (Wei, Yi \& Guo, 2014; Sushil, 2013). Most often organization are faced with resource scarcity and therefore their ability to switch the resource committed between strategic options to respond to changes in the business environment is curtailed (Wei, Yi \& Guo, 2014). High resource flexibility makes it easy to use the existing resources to pursue new strategic options as well as reducing the time and cost spent for switching one resource to another (Matthyssens, Pauwels \& Vandenbempt, 2005; Wei, Yi \& Guo, 2014). Resource flexibility is increased by building liquid resources and slack resource pool as well as the nature of the resources themselves. Specialized resources are important in building a firm's core competences but it is difficult to switch highly specialized resources from one use to another and these poses challenges to firm's when these resources becomes obsolete due to changes in the business environment.

Strategic action flexibility refers to capability for deployment of diverse strategic options in response to business environmental changes (Sopelana, Kunc, \& Herna'ez, 2014; Zahra, Hayton, Neubaum, Dibreil \& Craig, 2008). The degree of diversity of strategic options that a firm can deploy and the speed to which the firm can shift between these options has been positively related to firm performance (Sopelana et al., 2014; Nadkarni \& Narayanan, 2007; Nadkarni \& Herrmann, 2010; Mom, Van Den Bosh, \& Voberda, 2009; Cingoz, 2013).

Coordination flexibility refers to the ability of a firm to combine and deploy the existing resources in different ways to create new sets of resources in respond to changes in the business environment (Wei, Yi \& Guo, 2014). In dynamic environment, building sustainable competitive advantage calls for firms to invest in the capability to quickly shift its resource allocation and utilization to enable the firm shift strategic options quickly and fruitfully (Nadkarni \& Narayanan, 2007). Rigid resource deployment structure will lock firm resources in pursuing outdated strategies that may adversely affecting firm's performance in face of fast changing business environment (Thomson, Strickland, \& Gamble 2010). The need for resource deployment modification is essential condition for strategic flexibility (Nadkarni \& Narayanan, 2007; Cingoz, 2013).

Managerial Cognitive capability has been linked to strategic flexibility. For instant managerial mind-set inertia has be found to impede strategic change (Rosenbloom, 2000) while extant TMT mental models has been found to influence the way organizations structure their business operations (Laamanen \& Wallin, 2009). Similar Nadkarni and Barr, (2008) found out that the TMT correct interpretation of the cause-effect relationship between an environmental event and the firm's strategic action determined the speed of response to the changes in the industry environment. Kaplan, Murray, and Henderson, (2003) linked diversity in TMT mental models to diversity in strategic options which is echoed by the findings by Nadkarni and Narayanan, (2007) indicating that complexity of TMT strategic schemas was positively associated to resource deployment flexibility and the ability to shift between strategic options. Cho and Hambrick (2006) found out that the ability of a firm to quickly shift from one strategic option to another is influenced by the ability of its TMT to change their attention focus.

\subsection{Organizational Performance}

Organizational performance is not just the accomplishments of the intended outcomes of an organization as defined by Phillips and Moutinho, (2000) but the total sum of all processes and actions undertaken by managers in the present that are directed toward achieving particular set of goals in the future that are aimed at satisfying the needs of identified stakeholders (Connolly, Conlon, \& Deustch, 1980; Hitt, 1988; Zammuto, 1984) in better ways than similar organizations (Khatri \& Ng, 2000). This definition of performance brings forth components of performance that are similar to those identified by Carneiro, Silva, Rocha, and Dib, (2007) namely; organizational outcomes, satisfaction of stakeholders, performance time frame and performance reference point. This means that performance is multidimensional and consequently calls for use of multiples indicators to effectively measure performance (Glick, Washburn, \& Miller, 2005). The basis of choosing a dimension is the extent to which that dimension is relevance to a particular research (Richard, Devinney, Yip \& Johnson, 2009). 
Performance dimensions include operational performance (Combs, Crook \& Shook, 2005), stakeholder satisfaction (Freeman, 1984), financial performance (Cho \& Pucik, 2005) and lately the sustainability performance (Elkington, 1994). The financial dimension of performance includes the level of profitability, growth rate and market share ratio (Cho \& Pucik, 2005). Profitability level measures the net return on investment from a firm's strategies and operations (Glick, Washburn, \& Miller, 2005). Growth rate measures the ability to increase the size of a firm. Stakeholders' satisfaction dimension of performance measures the ability of the firm to provide quality products and services augmented with level of service delivery (Barney \& Clark, 2007) as well as level in investments in good human resources practices such as clearly defined job descriptions, training opportunities, clearly defined and followed career growth plans and fair remuneration policies (Harter, Schmidt, \& Hayes, 2002).

Sustainability dimension of performance takes into consideration a firm's degree of social responsibility, its economic value and its impact to the environment referred to as Triple Bottom Line (TBL) for measuring performance (Elkington, 1994). TBL broadens performance measurement beyond the traditional financial measure to include social and environmental considerations. TBL is intended to advance the goal of sustainability in business practices, by extending the focus of firms beyond profits to include social and environmental issues. TBL is usually difficult to measure because while it is easy to measure financial performance, social and environmental performance measurement is subjective in nature and thus difficult to standardize.

A number of studies have looked at the relationship between managerial cognition and performance. Gary and Wood (2011) found out that mental models accuracy and complexity positively and significantly influence performance. Li, Maggitti, Smith, Tesluk and Katila (2013) linked TMT's attention capability with firm innovation performance. Coltman, Devinney and Midgley, (2008) examined the effect of managerial cognitions on firm performance in dynamic business environments and found a positive relationship between the two. Bantel and Jackson (1989) found out that TMT cognitive capabilities and the TMT group dynamics affected decision quality. Gavetti, (2012) studied the root of superior organizational performance and found out that management of cognitive processes and strategic leader's ability to overcome cognitive biases underpinned superior performance. Tripsas and Gavetti, (2000) established that cognition was a central contributor to performance.

Empirical studies in the relationship between strategic flexibility and firm performance have yielded positive results. For instant strategic flexibility has been found to be positively related to superior firm performance (Nadkarni \& Narayanan, 2007; Combe et al., 2012; Lin et al., 2014). Strategic flexibility has also been found to improves decision process and reduce business risks (Ram'irez, Morales \& Aranda, 2012; Grewal \& Tansuhaj, 2001; Lee \& Makhija, 2009). In addition strategic flexibility improves organizational learning and thus increasing innovation performance and internal efficiency (Das \& Elango, 1995; Sanchez, 1995; Dibrell, Down \& Bull, 2007; Levy \& Powell, 1998; Javalgi, Whipple, Gosh \& Young, 2005). Strategic flexibility is also linked to increase in perceived service quality (Johnson, Lee, Sain \& Groshmann, 2003) and thus leading to increase in the reputation of the firm (de Soto-Camacho \& Vargas-S'anchez, 2015; Celuch, Silva, Rocha \& Dib, 2007; Gylling, Elliott \& Toivonen, 2012; Ling-Yee, \& Ogunmokun, 2013).

\subsection{Industry Velocity}

Industry velocity denotes the frequency, magnitude and predictability of the change of the various environmental features (Nadkarni \& Barr, 2008, Kim \& Rhee, 2009). Frequency refers to the time between subsequent environmental changes (Duncan, 1972; Jurkovich, 1974). Magnitude measures the extent to which two succeeding environmental events differ while predictability measures the ability to accurately anticipate a future environmental event (Wholey \& Brittain, 1989; Brown \& Eisenhardt, 1998; Eisenhardt \& Martin, 2000). The rate of obsolescence of existing firm resources, competencies and capabilities in high velocity industry environments is high (Fredrickson \& Mitchell, 1984) and therefore firms need to build new resources, competencies and capabilities to survive in such environments. This calls for dynamic capabilities to enable the firms to renew their resources, competencies and capabilities in order to align to shifting environmental conditions (Teece, Pisano \& Shuen, 1997).

According to Leaptrott and McDonald, (2015) how managers perceive the changes in the business environment determine how they will respond to those changes. High industry velocity makes it difficult for managers to accurately interpret the cause-and-effect relationships of environmental changes because of cognitive limitation to analyze all the information related to the environmental changes (Weick, 1995). This means the managers are not able to link their response for particular environmental events to desirable organizational outcomes. In the 
absence of clear understanding of the causal relationships between environmental events, strategic option, managerial action and organizational outcome managers, resort to use of heuristics to guide decision making and actions (Walsh, 1995). The ability to monitor industry changes is hampered by managers' cognitive limitation (Cho \& Hambrick, 2006; Cyert \& March, 1963). The cognitive limitation increases as the industry velocity increases (Nadkarni \& Barr, 2008). This means that managers in high industry environments should put in place measures to enhance their cognitive abilities in order to be able to shape their organizations future in the face of changing environmental realities (Leaptrott \& McDonald, 2015; Bogner \& Barr, 2000).

\subsection{Organizational Characteristics}

Strategic decision making process is affected by firm characteristics which include structure, size, age, culture, and inertia (Taslak, 2004; Adner \& Helfat, 2003). For example formal structures reduce TMT political dynamics and increase TMT rationality in decision making (Shrivastava \& Grant, 1985). Organizations with taller hierarchical structure are less flexible and therefore face challenges in changing their strategies to respond to business environment changes (Hill \& Jones, 2004). Organizations that have horizontal structures are able to increase their organizational creativity and innovation which enables them to make high quality strategic decisions as well as are able to switch between strategic options quickly and at low cost (Lubatkin, Pimpek, Ling, \& Veiga, 2006). Flatter organizational structure also enables organizational players to create synergies amidst themselves which increases organizational flexibility and performance (Mom et al., 2009).

The size of the organization also affects strategic decision making (Elbanna, 2009). Strategic decision making in small organizations is more informal than formal and largely depends on the capabilities of a few individuals while in large organizations, strategic decision making is more formal and takes a structured approach (Hart \& Banbury, 1994). This is because large firms have many employees which calls for several layers of managers and thus complicating the strategic decision making process (Child, 1972). On the other hand small organizations have few layers of management making information flow and decision making easy and fast (Brouthers, Andriessen, Nicolaes, , 1998). Large firms have the finances and other resources required to carry an elaborate strategy making process as compared to smaller ones. This enables them to make elaborate strategic decisions. Small organizations are more flexible than large ones and this makes them to be able to quickly change their strategies in response to changes in the business environment (Hitt et al., 2006).

Organization culture exhibited through its norms, values, and premises affects its strategic decision making. For organizations to make and implement strategic decisions, a tolerance culture is required that allows decision makers to scrutinize issues from different perspectives and consider broad range of alternative solutions especially in organizations operating in dynamic business environments (Mansood, Igbal \& Akbar, 2012; Korte, 2003). Culture that is harsh on mistakes or "competing culture" can divert managerial attention during strategic decision making (Shimizu \& Hitt, 2004; Mansood, Igbal \& Akbar, 2012). According to Carmeli and Tishler, (2012) a culture that builds mutual trust among the TMTs enables an organization to make comprehensive, effective and quick strategic choices. Creative culture improves the organizational flexibility that is necessary to responding to changes in the dynamic business environments (Tellis, Prabhu \& Chandy, 2009).

\subsection{Theoretical Review}

The conceptual review has revealed the nature and interactions of the key constructs of TMT cognitive capability, industry velocity, strategic choice, strategic flexibility and firm performance. This has raised issues that call for review of theories that can explain the nature and interactions of the constructs. This paper examined the Strategic Cognitive Perspective, Strategic Choice Theory, Behavioural Decision Theory, Attention Based Theory, Upper Echelon Theory, and Contingency Theory.

\subsubsection{Strategic Cognition Perspective}

Strategic Cognition Perspective (SCP) looks at strategic management from a cognitive view by linking strategic choices to managerial cognitive structures and processes (Hodgkinson \& Thomas, 1997; Porac \& Thomas, 2002). The cognitive structures forms the managers' view about the business environment, the available strategic alternatives, the strategies pursued by their competitors and the necessary actions the organization need to take to implement the selected strategies. The cognitive structures also enables the organization to undertake sense-making, sense-giving and interpretation in strategic decision making process (Porac \& Thomas, 2002). SCP explains how cognitive representation and the mental processes that underpin those cognitive representation develop and how they shape the strategies, actions and outcomes in organizations (Narayanan, Zane \& Kemmerer, 2011).

Extant literature has linked top managers' cognitive structures with strategic choices that an organization makes 
as a response to changes in the organization's industry environment (Narayanan, Zane \& Kemmerer, 2011). SCP scholars, are primarily interested in examining cognitive phenomena involved in strategy formulation and implementation, emphasizing top manager's cognition in the strategic context. SCP focuses on mental models and mental processes of the environmental events and the internal organization arrangements in respond to the environment events while fully acknowledging the role of cognitive biases and heuristics. SCP recognizes the role played by cognition in the link between TMT and strategic choices, actions and outcomes. From the review of the SCP, the authors were able to deduce the components of TMT cognitive capabilities and how they affect strategic decision making and organizational outcomes.

\subsubsection{Strategic Choice Theory}

Strategic Choice Theory (SCT) views strategy making process to be a political process whereby strategic choices and actions are decided upon by power holders within an organization and that the decisions made are influenced by and also shape the business environment (Child, 1972, 1997). SCT emphasizes that organizations' strategies emanate from the interaction between a firm's managers and its business environment. The strategic choices that an organization makes are constrained by events emanating from its business environment as well as the accuracy of its manager's interpretation of the environmental events. The organizational managers are also subject to their own interests which may influence negatively the organization's strategic making process. The environmental events as well as the managers interests, values and beliefs determines the choices the managers make which in turn determines the strategic direction of the organization. From the review of SCT the authors identified the interrelationship between the business environment and the choices the organizational executives make and the internal organizational characteristics that affect the choices made.

\subsubsection{Behavioural Decision Theory}

Behavioural Decision Theory (BDT) holds that organizational decision making process is subject to the limited capacity of human mind to collect and analyze information (Kahneman, Slovic, \& Tversky, 1982; Tversky \& Kahneman, 1974). Its premises are based on the concept of bounded rationality (Simon, 1978), which beliefs that the human mind is limited by the amount of information it can store and process in a particular time. Due to bounded rationality manager tend to make satisfying decisions rather than optimal ones for a particular situation through their own judgment or heuristic decision making. Heuristic decision making leads to decision biases because they fail to analyze all the options in arriving at the selected options. The concept of bounded rationality can be explained by the Information Processing Theory (IPT).

IPT posits that the human mind is an information processor that is capable of receiving information signal, storing it, processing it and producing an action (Broadbent, 1958). This explains why human being do not merely respond to information stimuli but process it before responding. The human mind is usually bombarded by a lot of information stimuli from the environment but the mind selects one of the stimuli for processing based on its features while the other stimuli are store in the mind for some time and then they dissipate away. The limitation in the amount of information that human mind can sense, process, store and retrieve at a particular time explains the concept of irrationality in decision making of the managers (Miller, 2011). The limited cognitive capability of the human mind means limited ability to perceive, attend, interpret and act by managers on the environmental contingencies of their organizations. Insight from BDT reveal that people's choices are directly linked to their information processing capacity. The review of the BDT brings fourth the understanding that managers are cognitively endowed differently and therefore their capacity to process information is different. This supports the argument for cognitive capability affecting TMT decision making and consequently organizational outcomes.

\subsubsection{Attention Based Theory}

Attention Based View (ABT) holds that managers operate in a complex business environment that is impossible to fully comprehend and therefore they employ selective attention in order to understand their business environment (Ocasio, 1997). Due to the selective attention, managers result to simplification of the environment events in order understand them and respond to them through choices and actions. The selectivity in attention of a particular manager is determined by their personality, their past experience and the firm's characteristics such as culture, structure and past performance. ATB indicate that attention structures affects managerial focus. Attention can be considered a mediator between the mental structures and the decision-making process. Managers can only make sense of and act on issues that have attracted their attention (Ocasio, 1997).

ABT bring forth the understanding that managerial attention is limited. This is because the manager's mind is rationally bounded (Cyert \& March, 1963) while the environment events to be attended to are unlimited. Also the outcome of managerial attention is affected by the complexity of the environmental events especially in dynamic 
environments. For instance the most salient features of an environmental event may be of lesser important in strategic decisions making at a particular time compared to those that are less salient (Garg, Walters, \& Priem, 2003). This is supported by Rerup, (2009) argument that weak cues in the environment can contain information regarding threats or opportunities with significant consequences for the organization.

Yu, Engleman, and Van de Ven, (2005) argues that attention is affected by the manager's mental schemes and structures as well as the organization's structure and culture. Ocasio (2011) identified two distinct processes in how a decision maker selects the focus of their attention. First is the top-down process which argues that goals, task demands and prior cognitive orientations select the focus of attention. The other is the bottom-up approach which deals with the characteristics of the environmental event and what makes them stand out amongst others (Ocasio, 2011).

Another factor that influences managerial attention is organizational identity (Weick, 1995). Organizational identity is central to organizational behaviour and based on the sense of belonging by the organization members (Gioia, 2008). Identity is interwoven with the deepest level of sense-making and understanding and thus central to managerial attention (Gioia, 2008). From the review of the ABT the authors identified components of TMT cognitive capability and how each of these components affect the TMT choices as well as the resultant organizational outcomes. The review also highlighted the interrelationship between the TMT cognitive capability components and the external and internal organizational environments.

\subsubsection{Upper Echelon Theory}

Upper Echelon Theory (UET) holds that organizational strategies and their outcomes reflect the decisions made by the organization's TMT (Hambrick \& Mason, 1984). The decision made by the organization is subject to the TMT's beliefs, values, personalities and cognitive ability. The values, beliefs, personalities, manager's experience and cognitive abilities affect the ability of the top managers to understand and respond to the environmental events (Hambrick, 2007; Gerstner, König, Enders, \& Hambrick, 2013). According to UET, due to the dynamism of the business environment managers are bombarded with a lot of information to perceive, attend to and interpret beyond their mental capacity which makes managers resort to use of heuristics in decision making. Given these theoretical insights in UET, it is clear that the organizational strategic outcomes are directly linked to the organizational decision maker's cognitive information processing capacity. From this theory one can clearly see that an organizational strategic decisions and outcomes depend largely on its TMT decisions and the TMT decisions are largely depended on the TMT cognitive capabilities.

\subsubsection{Contingency Theory}

Contingency theory holds that organizations are contingent upon their environment due to the uncertainty of the environment and the fact that the environment determines the choices the organizations make and the outcomes of those choices (Galbraith, 1977). The environmental uncertainty is determined by the amount of information the organization can process compared to the total amount of information exhibited by the environment event. And since the amount of information an organization can process in dependent on the cognitive ability of its TMT (Hambrick \& Mason, 1984), then environment uncertainty caused by the gap between overall TMT cognition level and the cognition required to completely process the total information from the environment event. And again since environment uncertainty causes environment complexity then the gap between the level on TMT cognition and the cognition required to fully understand the environmental event determines the complexity of the environment that confronts an organization and which determines the organization's strategic choices and outcomes (Nobre, Tobias \& Walker, 2010). From the review of this theory the authors established that TMT cognitive capability is important in addressing environmental uncertainty and complexity in strategic decision making. This supports the arguments of this paper linking TMT cognitive capability with organization outcomes in high velocity industry environments.

\subsection{The Case for a Theoretical Model}

The theoretical review has raised issues that support a case for a new model linking TMT cognitive capability, industry velocity, strategic choice, strategic flexibility, organizational characteristics and performance. The first issue is expansion of the indicators to operationalize the constructs beyond what has been used in extant literature. These indicators have been derived from conceptual and theoretical review and require empirical investigations to better understand their exact behaviour in practice. This expansion enhances the conceptualization of these constructs, and the accuracy of their measurement and the measurement of their interrelationships. This makes empirical testing of these constructs more logical and facilitates in-depth analysis of their relationships as well as the ability to make clear inferences and conclusions. 
The second issue is the emergent phenomenon arising from the new conceptualization that puts together organizational capability in the form of TMT cognitive capability from the RBV with industry velocity from the industrial organization perspective, strategic choice from the strategic choice perspective and organizational characteristics and performance from organizational theory to explain strategic decision making and outcomes in organizations. This integrative perspective offers an opportunity to address the limitations of the propositions of each of the perspectives individually (Eisenhardt \& Martin, 2000). A theoretical model will therefore provide a clear logical linkage between the identified constructs in this new integrative perspective.

The third issue is the emergence of new paradigm in the organizational management epistemology especially in relation to strategic decision making and outcomes. The theoretical review has shown that the epistemology in organizational strategic decision making has followed two sets of paradigms. One advocates for a deterministic approach where varying environmental conditions are seen as the only determinant of organizational actions and that management do not play any role while the second advocates for resource-capability-competence understanding in strategic decision making and outcomes (Nadkarni \& Barr, 2008). The resource-capability-competency paradigm argues that strategic decisions and outcomes emanate purely from the resources that an organization is able to control and its capability and competences to configure, re-configure and utilize these resources (Barney, 1991; Teece, 2007). This paradigm beliefs that the external environment does not play any role in strategic decision making and outcomes. The new paradigm emanating from this paper is a blend of the earlier two arguments which beliefs that both the environment and organizational capability affect strategic decisions and outcomes. This new paradigm hold that organizational strategic decision making and outcomes are affected by its resources, capabilities and competences and the nature of its industry environment.

The fourth issue that supports the call for a new theoretical model is the fact that extant empirical studies on managerial cognition and organizational outcomes have produced mixed results, some indicating significant positive relationship while others posting insignificant relationships. The mixed results can be attributed to methodological limitation of relying on demographic characteristics as proxies for measuring managerial cognitive capacity and failing to measure the managerial psychological and mental characteristics directly (Hambrick, 2007, Eggers \& Kaplan, 2009, Kaplan, 2011, Helfat \& Peteraf, 2015).

\section{The Proposed Theoretical Model}

In view of the above arguments, the authors propose a new model linking TMT cognitive capability, strategic choice, industry velocity, strategic flexibility, organizational characteristics and performance. The proposed model shows how the constructs relate to each other as well as the indicators for measuring each of the constructs. 


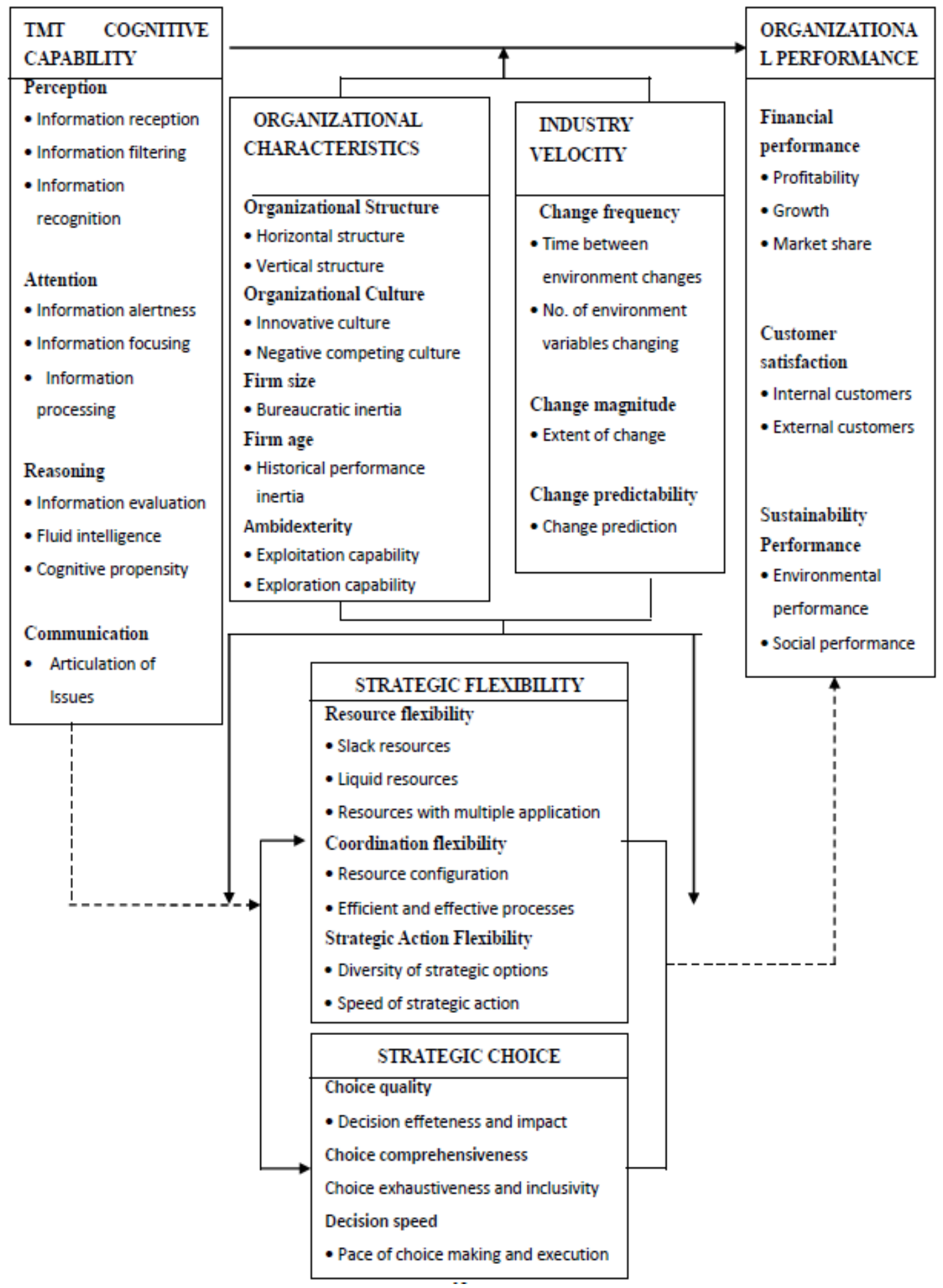

Figure 1. Theoretical model linking TMT Cognitive Capability, Strategic Choice, Strategic Flexibility, Industry Velocity, Organizational Characteristics and Performance

\subsection{TMT Cognitive Capability and Organizational Performance}

Sustainable performance will require that firms not only continuously adapt to but also shape their business environment. The adaptation and shaping of the environment will require the firm's TMT sense, interpret and act on the information from the business environment. This requires managerial capabilities of perception, attention, interpretation, and reasoning (Helfat \& Peteraf, 2015). Mental processes and mental representations significantly influence the managers' cognitive capabilities and consequently the quality of subsequent strategic choices and 
actions (Narayanan, Zane, \& Kemmerer, 2011). Because of cognitive biases, managers may fail to see opportunities or threats, might not give them enough weight, may fail to consider all possible responses, and therefore may resort to adopting suboptimal choices (Ocasio, 2011). How decision-makers respond to particular environmental events depends on how they interpret them and their interpretations are deeply rooted in their mental structures and their organization's attention structure and deployment (Ocasio, 1997). The responses TMTs make are expected to be well thought out ones with potential to optimize on the opportunities availed to the organization so as to drive the organization towards its desired direction. Therefore, the deployment of TMT cognitive capability stands to enhance the performance of the organization. Thus, we propose:

Proposition 1: There is a correlation between the Deployment of a firm's TMT Cognitive Capabilities and its performance.

\subsection{The Role of Strategic Choice and Strategic Flexibility}

The conceptual and theoretical review has shown that the capabilities for strategic flexibility are depended on information processing capabilities of a firm's TMT. This is in line with Sharfman and Dean (1997) findings that information processing is central to strategic options generation to enhance a firm's strategic flexibility. TMT cognitive capability is thus essential to choice and action because what the TMT decides is linked to the meaning it gives to the current situation (Garvetti \& Warglien 2015). The cognitive models developed by the TMT to understand the business environment affect diversity of strategic options, and hence strategic flexibility. This is also supported by Nadkarni and Narayanan, (2007) assertion that cognitive representation influences strategic flexibility capability through biased understanding of the business environment. The cognitive schemas influence the ability for advance recognition of changes in the business environment which is an antecedent to strategic flexibility. Thus we propose that: -

Proposition 2a: There is a correlation between Deployment of TMT Cognitive Capabilities and a firm's Strategic Choice.

Proposition 2b: There is a correlation between Deployment of TMT Cognitive Capabilities and the firm's extent of Strategic Flexibility.

Strategic flexibility enables firms to achieve sustainable competitive advantage by building in them a dynamic capability for switching from one strategic alternative to another. The distinctive competitive advantage arising from strategic flexibility emanates from the fact that a flexible firm is able to generate diverse strategic alternatives and commit flexible resources that enables the firm to pursue the diverse strategic alternatives and also be able to quickly switch between those alternatives. This enables the firm to deal with dynamic business environments in a manners that the competitors cannot imitate (Sanchez, 1995).

In addition strategic flexibility enables firms to perceive, attend to and interpret their environment better than inflexible firms. This enables them to utilize opportunities from the environment as well as neutralize any threat emanating from the environment. Strategic flexibility is positively related to firm performance in high velocity industries or in dynamic business environments (Grewal \& Tansuhaj, 2001; Zhang, 2006; Nadkarni \& Narayanan, 2007). Firms that are able to quickly redeploy resources to execute diverse strategic options have the ability to stay ahead of the competition and achieve sustainable performance (Grewal \& Tansuhaj, 2001; Teece, 2007). Thus, we propose that:

Proposition 2c: Strategic Choice mediates the relationship between Deployment of a firm's TMT cognitive capabilities and its performance.

Proposition 2d: Strategic Flexibility mediates the relationship between Deployment of a firm's TMT cognitive capabilities and its performance.

\subsection{The Role of Industry Velocity and Organizational Characteristics}

The magnitude, rate of change and change predictability of the industry environment properties will affect the accuracy of the TMT mental model. The accuracy of the TMT mental model will affect the organization's strategic fit which in turn will affect the organization's performance. High velocity industry demands for high cognitive capacity in order to minimize cognitive bias as compared to stable industry. Cognitive bias will lead to strategic blunder that will affect organizational performance. In addition industry velocity affects the rate of obsolescence of organizational strategies. This means that organizations operating in high industry velocities should frequently change their strategies in order to attain sustainable competitive advantage.

The manager's ability to accurately recognize, interpret and make sense of the turbulent and uncertain environment will be affected by the manager's mental state. Organizational characteristics affect significantly the 
mental states of managers. Organizational size, structure and culture affects the flow of information and ideas within an organization and thus affecting the managers ability to expand their cognitive capacity by learning from others within and from outside the organization. Small organizations, flat structured organizations and organizations with culture that encourages free flow of information and knowledge enhance the mental state of their managers' which in turn leads to high mental model accuracy of the managers and consequently sustained strategic fit and organizational performance. Contrary, large organizations, high hierarchical organizations and organizations with culture of information and knowledge holding will hinder the expansion of their managers' mental model accuracy, resulting to strategic blunders and poor performance.

Managers that seek to build strategic flexibility in their firms should develop flat organizational structure and organization culture that encourages free sharing of information. Flatter organizational structure encourage information flow and creativity within an organization. Highly hierarchical organizational structure hinders managers' ability to response to changes in the business environment (Hill \& Jones, 2004). Organizations with flat structures are able to quickly make and execute strategic decision. Also, small organizations are able to make and implement decisions quickly than large ones. The flexibility of small firms enables them to develop variety of strategic alternatives than large ones (Hitt et al., 2007). Moreover, ambidextrous organizations have the ability to exploit existing strategic options and at the same time explore for new strategic options in order to adapt to changing business environment (Lubatkin et al., 2006). Thus, we propose:

Proposition 3a: Organizational Characteristics such as size, structure, culture and ambidexterity will moderate the relationship between Deployment of its TMT Cognitive Capabilities and Strategic Flexibility.

Proposition 3b: Industry Velocity will moderate the relationship between the Deployment of TMT Cognitive Capabilities and Strategic Flexibility.

Proposition 3c: Organizational Characteristics such as size, structure, culture and ambidexterity will moderate the mediated effect of Strategic Flexibility on the relationship between the Deployment of TMT Cognitive Capabilities and the Organizational Performance.

Proposition 3d: Industry Velocity will moderate the mediated effect of Strategic Flexibility on the relationship between the Deployment of Cognitive Capabilities and the Organizational Performance

Proposition 3e: Organizational Characteristics such as size, structure, culture and ambidexterity will moderate the relationship between the Deployment of TMT Cognitive Capabilities and Organizational Performance.

Proposition 3f: Industry Velocity will moderate the relationship between Deployment of TMT Cognitive Capabilities and Organizational Performance.

\section{Conclusion}

The purpose of this paper was to explore the construct of TMT cognitive capability with a view to highlighting its outcomes in the context of dynamic environments and propose a theoretical model that describes the emerging phenomenon. Towards this, the authors reviewed extant conceptual, theoretical and empirical literature that comprehensively explored the nature of the construct of TMT cognitive capability and identified a relevant set of components that when unleashed into an organizational system bring about a phenomenon characterised by both intermediate and ultimate outcomes. The intermediate outcomes were identified as strategic choice and strategic flexibility while the ultimate outcome was presented as performance. The phenomenon involving the constructs of TMT Cognitive Capability, strategic choice, flexibility and performance was proposed to be influenced by the characteristics of the firm and the level of industry velocity experienced by each firm.

In order to fully explain the emerging phenomenon, the authors anchored their arguments on Strategic Cognition Perspective, Behavioural Decision Theory, Attention Based Theory, Upper Echelon Theory and Contingency Theory and proposed a theoretical model linking the constructs of the study. Extant literature reviewed indicates that the TMT cognitive capabilities of perception, attention, interpretation and reasoning are antecedent factors to a firm's strategic flexibility and choice by determining the extent to which the correct and full information about the environment attributes is timely obtained and how much focus is given to all the facts emanating from that information, how accurate the cause-effect relationships among the environment variables are interpreted and the extent to which the results of this interpretation is used in strategic decision making and implementation. Thus, while TMT cognitive capability is presented as a factor explaining firm performance, the extent of explanation is both dependent and contingent upon strategic flexibility and choice and the firm's characteristics and environmental velocity.

In conclusion, therefore, the contents of the paper contribute towards the knowledge in strategic management by consolidating literature that gives rise to an understanding of the components of TMT Cognitive Capability from 
a multidisciplinary based body of knowledge. In addition, the paper proposes a suitable conceptual framework with an appropriate set of indicators that offer a potential guide to future empirical work. Researchers are therefore invited to consider the components of this model with a view to applying the constructs proposed and their operational indicators in empirical work. In proposing this model, we however note that it faces two limitations. First is the inadequate set of empirical work on TMT Cognitive Capability that limits the scope of understanding of its behaviour in practice. Secondly, the proposed propositions have not been backed by empirical data.

\section{References}

Abbott, A., \& Banerji, K. (2003). Strategic flexibility and firm performance: the case of US based transnational corporations. Global Journal of Flexible Management Systems, 4, 1-8.

Abrahamson, E., \& Hambrick, D. C. (1997). Attentional homogeneity in industries: The effect of discretion. Journal of Organizational Behaviour, 18, 513-532. https://doi.org/10.1002/(SICI)1099-1379(199711)18:1+<513::AID-JOB905>3.3.CO;2-\#

Adner, R., \& Helfat, C. (2003). Corporate effects and dynamic managerial capabilities. Strategic Management Journal, 24(10 SPEC ISS.). https://doi.org/10.1002/smj.331

Amason, A. C. (1996). Distinguishing the effects of functional and dysfunctional conflict on strategic decision making: Resolving a paradox for top management teams. Academy of Management Journal, 39, 123-148. https://doi.org/10.2307/256633

American Psychological Association. (2009). Glossary of psychological terms. Washington, DC: American Psychological Association.

Armstrong, S. J., \& Hird, A. (2009). Cognitive style and entrepreneurial drive of new and mature business owner-managers. Journal of Business and Psychology, 24, 419-430. https://doi.org/10.1007/s10869-009-9114-4

Armstrong, S. J., Cools E., \& Sadler-Smith, E. (2012). Role of cognitive styles in business and management: Reviewing 40 years of research. International Journal of Management Reviews, 14, 238-262. https://doi.org/10.1111/j.1468-2370.2011.00315.x

Bantel, A. K., \& Jackson, E. S. (1989). Top management and innovations in Banking: Does the composition of top management team make a difference? Strategic management Journal, 10(1), 107-124. https://doi.org/10.1002/smj.4250100709

Barney, J. (1991). Firm resources and sustained competitive advantage. Journal of Management, 17(1), 99-120. https://doi.org/10.1177\%2F014920639101700108

Barney, J., \& Clark, D. N. (2007). Resource-based theory. New York: Oxford.

Baron, R. A. (2006). Opportunity recognition as pattern recognition: how entrepreneurs "connect the dots" to identity. Academy of Management Perspectives 20(1), 104-119. https://doi.org/10.5465/amp.2006.19873412

Beach, L. R., \& Connolly, T. (2005). The Psychology of Decision Making: People in Organizations Thousand Oaks, CA: Sage Publications.

Bogner, W. C., \& Barr, P. S. (2000). Making sense in hypercompetitive environments: A cognitive explanation for the persistence of high velocity competition. Organization Science, 11, 212-226.

https://doi.org/10.1287/orsc.11.2.212.12511

Broadbent, D. (1958). Perception and communication. London: Pergamon Press. https://doi.org/10.1037/10037-000

Brouthers, K. D., Andriessen, F., \& Nicolaes, I. (1998). Driving blind: strategic decision-making in small companies. Long Range Planning, 31(1), 130-138. https://doi.org/10.1016/S0024-6301(97)00099-X

Brown, S. L., \& Eisenhardt, K. (1997). The art of continuous change: Linking complexity theory and time-paced evolution in relentlessly shifting organizations. Administrative Science Quarterly, 42, 1-34. https://doi.org/10.2307/2393807

Brozovic, D. (2018). Strategic flexibility: A review of the literature. International Journal of Management Reviews. 20, 3-31. https://doi.org/10.1111/ijmr.12111

Carmeli, A., \& Tishler, A. (2012). CEO relational leadership and strategic decision quality in top management teams: The role of team trust and learning from failure. Strategic Organization, 10(01), 31-54. 
https://doi.org/10.1177\%2F1476127011434797

Carneiro, J. M. T., Silva, J. F., Rocha, A., \& Dib, L. A. R. (2007). Building a Better Measure of business performance. RAC-Eletrônica, 1(2), 114-135.

Celuch, K., Murphy, G. B., \& Callaway, S. K. (2007). More bang for your buck: small firms and the importance of aligned information technology capabilities and strategic flexibility. Journal of High Technology Management Research, 17, 187-197. https://doi.org/10.1016/j.hitech.2006.11.006

Chen, M., Lin, H., \& Michel, J. G. (2010). Navigating in a hypercompetitive environment: the roles of action aggressiveness and TMT integration. Strategic Management Journal, 31(13) 1410-1413. https://doi.org/10.1002/smj.891

Child, J. (1972). Organizational structure, environment and performance: The role of strategic choice. Sociology, 6(1), 1-22. https://doi.org/10.1177\%2F0038038572 00600101

Child, J. (1997). Strategic choice in the analysis of action, structure, organizations and environment: Retrospect and Prospect. Organization Studies, 18(1), 43-76. https://doi.org/10.1177\%2F017084069701800104

Cho, H., \& Pucik, V. (2005). Relationship between innovativeness, quality, growth, profitability, and market value. Strategic Management Journal, 26(6), 555-575. https://doi.org/10.1002/smj.461

Cho, T. S., \& Hambrick, D. C. (2006). Attention as the mediator between top management team characteristics and strategic change: The case of airline deregulation. Organization Science, 17(4), 453-469. https://doi.org/10.1287/orsc. 1060.0192

Cingoz, A. (2013). Strategic flexibility, environmental dynamism, and innovation performance. Procedia - Social and Behavioral Sciences, 99, 582-589. https://doi.org/10.1016/j.sbspro.2013.10.528

Colman, A. M. (2006). A dictionary of psychology (2nd ed.). Oxford University Press: Oxford, U.K.

Coltman, T., Devinney T., \& Midgley, D. (2008). The value of managerial beliefs in turbulent environments. Journal of Strategy and Management, 1(2), 181-197. https://doi.org/10.1108/17554250810926366

Combe, I. A., Rudd, J. M., Leeflang, P. S. H., \& Greenley, G. E. (2012). Antecedents to strategic flexibility: management cognition, firm resources and strategic options. European Journal of Marketing, 46, 1320-1339. https://doi.org/10.1108/03090 561211248053

Combs, J. G., Crook, T. R., \& Shook, C. L. (2005). The dimension of organizational performance and its implications for strategic management research. In D. J. Ketchen \& D. D. Bergh (Eds.). Research methodology in strategy and management (pp. 259-286). San Diego: Elsevier. https://doi.org/10.1016/S1479-8387(05)02011-4

Connolly, T., Conlon, E. J., \& Deutsch, S. J. (1980). Organizational effectiveness: a multiple-constituencies approach. Academy of Management Review, 5(2), 211-217. https://doi.org/10.5465/amr.1980.4288727

Cyert, R. M., \& March, J. G. (1963). A Behavioral Theory of the Firm. Englewood Cliffs, NJ: Prentice-Hall.

Daft, R., \& Weick, K. (1984). Toward a model of organizations as interpretation systems. The Academy of Management Review, 9(2), 284-295. https://doi.org /10.5465/amr. 1984.4277657

Das, T. K., \& Elango, B. (1995). Managing strategic flexibility: key to effective performance. Journal of General Management, 20, 60-75. https://doi.org/10.1177\%2F030630 709502000305

de Soto-Camacho, E. G., \& Vargas-S'anchez, A. (2015). Choice of entry mode, strategic flexibility and performance of international strategy in hotel chains: an approach based on real options. European Journal of Tourism Research, 9, 92-114.

Dean, J. W., \& Sharfman, M. P. (1996). Does decision process matter? A study of strategic decision making effectiveness. Academy of Management Journal, 39, 368-396. https://doi.org/10.2307/256784

Dibrell, C., Down, J. \& Bull, L. (2007). Dynamic strategic planning: achieving strategic flexibility through formalization. Journal of Business and Management, 13, 21-35.

Duncan, R. (1972). Characteristics of organizational environments and perceived environmental uncertainty. Administrative Science Quarterly 17, 313-327. https://doi.org/10.2307/2392145

Dutton, J. E., Fahey, L., \& Narayanan, V., K. (1983). Toward understanding strategic issue diagnosis. Strategic Management Journal 4(4), 307-323. https://doi.org/10.1002/smj. 4250040403

Eggers, J. P., \& Kaplan, S. (2009). Cognition and Renewal: Comparing CEO and organizational effects on 
incumbent adaptation to technical change. Organization Science, 20(2), 461-477. https://doi.org/10.1287/orsc.1080.0401

Eisenhardt, K. M. (1989). Making fast strategic decisions in high-velocity environments. Academy of Management Journal, 32, 543-576. https://doi.org/10.5465/256434

Eisenhardt, K., \& Martin, J. (2000). Dynamic capabilities: what are they? Strategic Management Journal, $21(10-11), 1105-1121$. https://doi.org/10.1002/1097-0266(200010/11)21:10/11<1105::AID-SMJ133>3.0.CO;2-E

Elbanna, S. (2006). Strategic decision-making: Process perspectives. International Journal of Management Reviews, 8, 1-20. https://doi.org/10.1111/j.1468-2370.2006.00118.x

Elbanna, S. (2009). Determinants of strategic planning effectiveness: extension of earlier work. Journal of Strategy and Management, 2(2), 175-187. https://doi.org/10.1108/17554250910965326

Elkington, J. (1994). Towards the sustainable corporation: Win-Win-Win business strategies for sustainable development. California Management Review, 36(2), 90-100. https://doi.org/10.2307/41165746

Escrig-Tena, A. B., Bou-Llusar, J. C., Beltr'an-Mart'in, I. \& Roca-Puig, V. (2011). Modelling the implications of quality management elements on strategic flexibility. Advances in Decision Sciences. https://doi.org/10.1155/2011/694080

Fredrickson, J. W., \& T. R. Mitchell (1984). Strategic decision process: comprehensiveness and performance in an industry with an unstable environment. Academy of Management Journal, 27(2), 399-423. https://doi.org/10.2307/255932

Frolick, M., \& Ariyachandra, T. (2006). Business performance management: one truth. Information Systems Management, 23(1), 41. https://doi.org/10.1201/1078.10580530/45769.23.1.20061201/91771.5

Galbraith, J. R. (1977). Organization design. Reading, MA: Addison-Wesley.

Garg, V. K., Walters, B. A., \& Priem, R. L. (2003). Chief executive scanning emphases, Environmental dynamism, and manufacturing firm performance. Strategic Management Journal, 24(8), 725-744. https://doi.org/10.1002/smj.335

Gary, M., \& Wood, R. (2011). Mental models, decision rules and performance heterogeneity. Strategic management Journal, 32(6), 569-594. https://doi.org/10.1002/smj.899

Gavetti, G. (2005). Cognition and hierarchy: Rethinking the micro foundations of capabilities development. Organization Science, 16, 599-617. https://doi.org/10.1287/orsc.1050.0140

Gavetti, G. (2012). Toward a behavioural theory of strategy. Organization Science, 23(1), 267-285. https://doi.org/10.1287/orsc.1110.0644

Gavetti, G., \& Warglien, M. (2015). A model of Collective Intetrpretation. Organization Science. ISSN 1047-7039. https://doi.org/10.1287/orsc.2015.0987

Gazzaniga, M., Heatherton, T., \& Halpern, D. (2010). Psychological Science, Norton: New York.

Gersttner, W., Konig, A., Enders, A., \& Hamrick, D. C. (2013). CEO narcissism, audience engagement, and organizational adoption of technological discontinuities. Administrative Science Quarterly, 58(2), 257-291. https://doi.org/10.1177/0001839213488773

Gioia, D. A. (2008). Organizational identity as an emerging perennial domain. In Barry, D. \& Hansen, H. (Eds.), The SAGE Handbook of New Approaches in Management and Organization. (pp. 63-66). London: SAGE Publications Ltd. https://doi.org/10.4135/9781849200394.n9

Glick, W. H., Washburn, N. T., \& Miller, C. C. (2005). The myth of firm performance. Proceedings of the Annual Meeting of American Academy of Management. Honolulu, Hawaii.

Grewal, R., \& Tansuhaj, P. (2001). Building organizational capabilities for managing economic crises: the role of market orientation and strategic flexibility. Journal of Marketing, 65, 67-80. https://doi.org/10.1509\%2Fjmkg.65.2.67.18259

Gylling, C., Elliott, R., \& Toivonen, M. (2012). Co-creation of meaning as a prerequisite for market-focused strategic flexibility. European Journal of Marketing, 46, 1283-1301. https://doi.org/10.1108/03090561211248035

Hambrick, D. C. (2007). Upper echelons theory: An update. Academy of Management Review, 32(2), 334-343. 
https://doi.org/10.5465/AMR.2007.24345254

Hambrick, D. C., \& Finkelstein, S. (1987). Managerial discretion: A bridge between polar views of organizational outcomes. In Cummings, L.L. \& Staw, B.M. (Eds), Research in Organizational Behavior, 9, JAI Press, Greenwich, CT, 369-406.

Hambrick, D. C., \& Mason, P. A. (1984). Upper Echelons: The Organization as a reflection of its top managers. Academy of Management Review, 9(2), 193-206. https://doi.org/10.5465/amr.1984.4277628

Hart, S. L., \& Banbury, C. (1994). How strategy-making processes can make a difference. Strategic Management Journal, 15(4), 251-269. https://doi.org/10.1002/smj.4250150402

Harter, J. K., Schmidt, F. L., \& Hayes, T. (2002). Business-unit-level relationship between employee satisfaction: A meta-analysis. Journal of Applied Psychology, 87(2), 268-279. https://doi.org/10.1037//0021-9010.87.2.268

Helfat, C. E., \& Peteraf, M. A. (2015). Managerial cognitive capabilities and the microfoundations of dynamic capabilities. Strategic Management Journal, 36(6), 831-850. https://doi.org/10.1002/smj.2247

Hill, W. L. C., \& Jones, G. R. (2008), Strategic management: An integrated approach, $8^{\text {th }}$ Ed., Houghton Mifflin Company, Boston.

Hitt, M. A., Keats, B. W., \& DeMarrie, S. M. (1998). Navigating in the new competitive landscape: Building strategic flexibility and competitive advantage in the 21st century. Academy of Management Executive, 12, 22-42. https://doi.org/10.5465/ame.1998.1333922

Hitt, M. A., Uhlenbruck, K., \& Shimizu, K. (2006). The importance of resources in the internationalization of professional service firms: the good, the bad, and the ugly. Academy of Management Journal, 49(6), 1137-1157. https://doi.org/10.5465/amj.2006.23478217

Hodgkinson, G. P., \& Healey, M. P. (2011). Psychological foundations of dynamic capabilities: Reflexion and reflection in strategic management. Strategic Management Journal, 32, 1500-1516. https://doi.org/10.1002/smj.964

Hodgkinson, G. P., \& Thomas, A. B. (1997). Editorial introduction to the special issue: Thinking in organizations. Journal of Management Studies, 34, 845-850. https://doi.org/10.1111/1467-6486.00074

Huff, A. S. (1990). Mapping strategic thought. John Wiley \& Sons: Chichester, UK.

Javalgi, R. R. G., Whipple, T. W., Ghosh, A. K. \& Young, R.B. (2005). Market orientation, strategic flexibility, and performance: Implications for services providers. Journal of Services Marketing, 19, 212-221. https://doi.org/10.1108/08876040510605244

Johnson, J. L., Lee, R. P. W., Saini, A. \& Grohmann, B. (2003). Market-focused strategic flexibility: conceptual advances and an integrative model. Journal of the Academy of Marketing Science, 31, 74-89. https://doi.org/10.1177/0092070302238603

Jurkovich, R. (1974). A core typology of organizational environments. Administrative Science Quarterly, 19(3), 380. https://doi.org/10.2307/2391979

Kahneman D. (2011). Thinking Fast and Slow. Farrar, Straus and Giroux: New York.

Kahneman, D., Slovic, P., \& Tversky, A. (1982). Judgment under uncertainty: Heuristics and biases. Cambridge University Press: New York. https://doi.org/10.1017/CBO9780511809477

Kaplan, S. (2011). Research in cognition and strategy: Reflections on two decades of progress and a look to the future. Journal of Management Studies, 48(3), 665-695. https://doi.org/10.1111/j.1467-6486.2010.00983.x

Kaplan, S., \& Tripsas, M. (2008). Thinking about technology: Applying a cognitive lens to technical change. Research Policy, 37(5), 790-805. https://doi.org/10.1016/j.respol.2008.02.002

Kaplan, S., Murray, F., \& Henderson, R. (2003). Discontinuities and senior management: Assessing the role of recognition in pharmaceutical firm response to biotechnology. Industrial and Corporate Change, 12, 203-233. https://doi.org/10.1093/icc/12.2.203

Khatri, N., \& Ng, H. A., (2000) The role of intuition in strategic decision making. Human Relations, 53(1), 57-86. https://doi.org/10.1177\%2F0018726700531004

Kilika, J. M. (2012): Entrepreneurship, human resource development and national innovation systems. The Digest 5, 147-156. 
Korte, R. F. (2003). Biases in decision making and implications for human resource development. Advances in Developing Human Resources, 5(4), 440-457. https://doi.org/10.1177\%2F1523422303257287

Kosslyn, S. M., \& Rosenberg, R. S. (2006). Psychology in Context. Allyn and Bacon: Boston.

Laamanen, T., \& Wallin, J. (2009). Cognitive dynamics of capability development paths. Journal of Management Studies, 46, 950-981. https://doi.org/10.1111/j.1467-6486.2009.00823.x

Leaptrott, J., \& McDonald, J. M. (2015). Perceived environmental sector importance as a determinant of managerial information search behavior. Academy of Strategic Management Journal, 14(1), 43-57.

Lee, S. H., \& Makhija, M. (2009). Flexibility in internationalization: is it valuable during an economic crisis? Strategic Management Journal, 30, 537-555. https://doi.org/10.1002/smj.742

Levy, M., \& Powell, P. (1998). SME flexibility and the role of information systems. Small Business Economics, 11, 183-196. https://doi.org/10.1023/A:1007912714741

Li, Q., Maggitti, P., Smith, K., Tesluk, P. \& Katila, R. (2013). Top management attention to innovation: The role of search selection and intensity in new product introductions. Academy of Management Journal, 56(3), 893-916. https://doi.org/10.5465/amj.2010.0844

Li, Y., Liu, Y., \& Duan, Y. (2008). Entrepreneurial orientation, strategic flexibilities and indigenous firm innovation in transitional China. International Journal of Technology Management, 41, 223-246. https://doi.org/10.1504/IJTM.2008.015993

Lieberman, M. B., \& Montgomery, D. B. (1988). First-mover advantages. Strategic Management Journal, 9, 41-58. https://doi.org/10.1002/smj.4250090706

Ling-Yee, L., \& Ogunmokun, G. (2013). The effect of marketing capability, financing resource and spatial configuration on market-focused flexibility. International Journal of Trade and Global Markets, 6, 158-181. https://doi.org/10.1504/IJTGM.2013.053004

Lubatkin, M. H., Pimpek, Z., Ling, Y., \& Veiga, J. F. (2006). Ambidexterity and performance in small to medium-sized firms: The pivotal role of top management team behavioural integration. Journal of Management, 32, 646-672. https://doi.org/10.1177\%2F0149206306290712

Massood. H., Igbal, S., \& Usman, A. (2015). Strategic decision making in cultural context. The Effect of Culture on Strategic Decision Making Process and its Incorporation. Scientific and academic publishing.

Matthyssens, P., Pauwels, P., \& Vandenbempt, K. (2005). Strategic flexibility, rigidity and barriers to the development of absorptive capacity in business markets: Themes and research perspectives. Industrial Marketing Management, 34(6), 547-554. https://doi.org/10.1016/j.indmarman.2005.03.004

Meyer, K. E., Estrin, S., Bhaumik, S. K., \& Peng, M. W. (2009). Institutions, resources, and entry strategies in emerging economies. Strategic Management Journal, 30, 61-80. https://doi.org/10.1002/smj.720

Miller, S. (2011). Student voices for change. Learning and leading with technology, International Society for Technology in Education. 38(8), 20-23.

Moldoveanu, M. (2009). Thinking Strategically About Thinking Strategically: The Computational Structure and Dynamics of Managerial Problem Selection and Formulation. Strategic Management Journal, 30, 737-763. https://doi.org/10.1002/smj.757

Mom, T. J., Van Den Bosch, F. A., \& Volberda, H. W. (2009). Understanding variation in managers' ambidexterity: Investigating direct and interaction effects of formal structural and personal coordination mechanisms. Organization Science, 20(4), 812-828. https://doi.org/10.1287/orsc.1090.0427

Muithya, V. M., \& Kilika, J. M. (2019). TMT diversity outcomes under environmental Contexts: A Review of literature and research agenda. Journal of Management and Strategy, 10(1), 43-62. https://doi.org/10.5430/jms.v10n1p43

Nadkarni, S., \& Barr, P. (2008). Environmental context, managerial cognition, and strategic action: An integrated view. Strategic Management Journal, 29, 1395-1427. https://doi.org/10.1002/smj.717

Nadkarni, S., \& Herrmann, P. (2010). CEO personality, strategic flexibility, and firm performance: the case of the Indian business process outsourcing industry. Academy of Management Journal, 53, 1050-1073. https://doi.org/10.5465/AMJ.2010.54533196

Nadkarni, S., \& Narayanan, V. K. (2007). Strategic schemas, strategic flexibility, and firm performance: The moderating role of industry clock speed. Strategic Management Journal, 28(3), 243-270. 
https://doi.org/10.1002/smj.576

Najmaei, A., \& Sadeghinejad, Z. (2016). Metacognition in strategic decision making: An integrated review and a research agenda. Information Age Publishing. 49-81. https://doi.org/10.1186/s13643-015-0101-8

NAMHC. (1996). Basic behavioral science research for mental health: perception, attention, learning, and memory. American Psychologist, 51(2), 133-142. https://doi.org/10.1037/0003-066X.51.2.133

Narayanan, V. K., Zane, L. J., \& Kemmerer, B. (2011). The Cognitive Perspective in Strategy: An Integrative Review. Journal of Management, 37(1), 305-351. https://doi.org/10.1177\%2F0149206310383986

Nobre, F. S., Tobias, A. M., \& Walker D. S. (2010). A new contingency view of the organization: Managing complexity and uncertainty through cognition. Brazilian Administration Review, 7, 379-396. https://doi.org/10.1590/S1807-76922010000400005

Noteboom, B. (2009). A cognitive theory of the firm: Learning, governance and dynamic capabilities. Boston, MA: Edward Elgar. https://doi.org/10.4337/9781848447424

Ocasio, W. (1997). Towards an attention-based view of the firm. Strategic Management Journal, 18(Special), 187-206. https://doi.org/10.1002/(SICI)1097-0266(199707)18:1+<187::AID-SMJ936>3.3.CO;2-B

Ocasio, W. (2011). Attention to attention. Organization Science, 22(5), 1286-1296. https://doi.org/10.1287/orsc.1100.0602

Philip, P. A., \& Moutinho, L. (2000). Strategic planning index: A tool for measuring planning effectiveness. Journal of Travel Research, 38(4), 369-379. https://doi.org/10.1177/004728750003800405

Porac, J., \& Thomas, H. (2002). Managing cognition and strategy: Issues, trends and future directions. In A. Pettigrew, H. Thomas, \& R. Whittington (Eds.), Handbook of strategy and management: 165-181. London: Sage. https://doi.org/10.4135/9781848608313.n8

Posner, M., \& Petersen, S. (1990). The attention system of the human brain. Annual review of neuroscience 13, 25-42. https://doi.org/10.1146/annurev.ne.13.030190.000325

Powell, T. C., Lovallo, D., \& Caringal, C. (2006). Causal ambiguity, management perception, and firm performance. Academy of Management Review, 31(1), 175-196. https://doi.org/10.5465/amr.2006.19379630

Powell, T. C., Lovallo, D., \& Fox, C. R. (2011). Behavioural Strategy. Strategic Management Journal, 32(13), 1369-1386. https://doi.org/10.1002/smj.968

Ram'ırez, A. M., Morales, V. J. G., \& Aranda, D. A. (2012). Knowledge creation and flexibility of distribution of information. Industrial Management and Data Systems, 112, 166-185. https://doi.org/10.1108/02635571211204245

Rerup, C. (2009). Attentional triangulation: Learning from unexpected rare crises. Organization Science, 20(5), 876-893. https://doi.org/10.1287/orsc.1090.0467

Richard, P. J., Devinney, T. M., Yip, G. S., \& Johnson, G. (2009). Measuring organizational performance: Towards methodological best practice. Journal of Management, 35(3), 718-804. https://doi.org/10.1177\%2F0149206308330560

Roberts, N., \& Stockport, G. J. (2009). Defining strategic flexibility. Global Journal of Flexible Systems Management, 10, 27-32. https://doi.org/10.1007/BF03396553

Rosenbloom, R. S. (2000). Leadership, capabilities, and technological change: The transformation of NCR in the electronic era. Strategic Management Journal, 21, 1083-1103. https://doi.org/10.1002/1097-0266(200010/11)21:10/11<1083::AID-SMJ127>3.0.CO;2-4

Rudd, J. M., Greenley, G. E., Beatson, A.T. \& Lings, I. N. (2008). Strategic planning and performance: extending the debate. Journal of Business Research, 61, 99-108. https://doi.org/10.1016/j.jbusres.2007.06.014

Rueda, M. R., Posner, M. I., \& Rothbart, M. K. (2005). The development of executive attention: contributions to the emergence of self-regulation. Developmental Neuropsychology 28(2), 573-594. https://doi.org/10.1207/s15326942dn2802_2

Saini, A., \& Johnson J. L. (2005). Organizational capabilities in E-commerce: An empirical investigation of E-brokerage service providers. Journal of the Academy of Marketing Science, 33(3), 360-375. https://doi.org/10.1177\%2F0092070305276150

Sanchez, R. (1995). Strategic flexibility in product competition. Strategic Management Journal, 16, 135-159. 
https://doi.org/10.1002/smj.4250160921

Sanchez, R. (1997). Preparing for an uncertain future: managing organizations for strategic flexibility. International Studies of Management and Organization, 27, 71-94. https://doi.org/10.1080/00208825.1997.11656708

Sharfman, M. P., \& Dean, J. W. Jr. (1997). Flexibility in strategic decision making: informational and ideological perspectives. Journal of Management Studies, 34, 190-215. https://doi.org/10.1111/1467-6486.00048

Shimizu, K., \& Hitt, M. A. (2004). Strategic flexibility: organizational preparedness to reverse ineffective strategic decisions. Academy of Management Review, 18, 44-59. https://doi.org/10.5465/ame.2004.15268683

Shrivastava, P., \& Grant, J. H. (1985), Empirically derived models of strategic decision-making processes. Strategic Management Journal, 6, 97-113. https://doi.org/10.1002/smj.4250060202

Simon, H. A. (1978). Information-processing theory of human problem solving. Handbook of Learning and Cognitive Processes, 5, 271-295.

Simon, H. A. (1991). Bounded rationality and organizational learning. Organization Science, 2, 125-134. https://psycnet.apa.org/doi/10.1287/orsc.2.1.125

Sopelana, A., Kunc, M., \& Hernáez, O.R. (2014). Towards a dynamic model of organisational flexibility. Systemic Practice and Action Research, 27(2), 165-183. http://dx.doi.org/10.1007/s11213-012-9274-4

Spanos, Y. E., Zaralis, G., \& Lioukas, S. (2004). Strategy and industry effects on profitability: evidence from Greece. Strategic Management Journal, 25(2), 139-166. https://doi.org/10.1002/smj.369

Stanovich, K. E. (2009). What intelligence tests miss: The psychology of rational thought. Yale University Press: New Haven, CT.

Sushil (2013). Leveraging strategic change with continuity. Springer, India. https://doi.org/10.1007/978-81-322-0726-9_1

Sushil (2015). Strategic flexibility: the evolving paradigm of strategic management. Global Journal of Flexible Systems Management, 16, 113-114. https://doi.org/10.1007/s40171-015-0095-z

Tamayo-Torres, I., Ruiz-Moreno, A., \& Verd'u, A.J. (2010). The moderating effect of innovative capacity on the relationship between real options and strategic flexibility. Industrial Marketing Management, 39, 1120-1127. https://doi.org/10.1016/j.indmarman.2009.10.003

Tangen, S. (2004) Performance measurement: from philosophy to practice. International Journal of Productivity and Performance Management, 53(8), 726-737. https://doi.org/10.1108/17410400410569134

Taslak, S. (2004). Factors restricting success of strategic decisions: evidence from the Turkish textile industry. European Business Review, 16(2), 152-164. https://doi.org/10.1108/09555340410524256

Teece, D. J. (2007). Explicating dynamic capabilities: The nature and microfoundations of (Sustainable) enterprise performance. Strategic Management Journal, 28, 1319-1350. https://doi.org/10.1002/smj.640

Teece, D. J., Pisano, G. \& Shuen, A. (1997). Dynamic capabilities and strategic management. Strategic Management Journal, 18(7), 509-533. https://doi.org/10.1002/(SICI)1097-0266(199708)18:7\%3C509::AID-SMJ882\%3E3.0.CO;2-Z

Tellis, G. J., Prabhu, J. C. \& Chandy, R. K. (2009). Radical innovation across nations: the pre-eminence of corporate culture. Journal of Marketing, 73, 3-23. https://doi.org/10.1509/jmkg.73.1.3

Thagard, P. (1996). Mind: Introduction to cognitive science. Cambridge, MA.: MIT Press.

Thomson, A. A., Strickland, A. J., \& Gamble, J. E. (2010), Crafting and executing strategy: The Quest for Competitive Advantage: Concepts and Cases. McGraw-Hill/Irwin.

Tripsas, M., \& Gavetti, G. (2000). Capabilities, cognition, and inertia: Evidence from digital imaging. Strategic Management Journal, 21, 1147-1161. https://doi.org/10.1002/1097-0266(200010/11)21:10/11\%3C1147::AID-SMJ128\%3E3.0.CO;2-R

Tuggle, C. S., Schnatterly, K., \& Johnson, R. A. (2010). Attention patterns in the boardroom: How board composition and processes affect discussion of entrepreneurial issues. Academy of Management Journal 53(3), 550-571. https://doi.org/10.5465/AMJ.2010.51468687

Tversky, A., \& Kahneman, D. (1974). Judgment under uncertainty: heuristics and biases. Science, 185(4157), 
1124-1131. https://doi.org/10.1126/science.185.4157.1124

Ussahawanitchakit, P., \& Sriboonlue, P. (2011). Transformational leadership, strategic flexibility, learning capability, continuous improvement, and firm performance: Evidence from Thailand. International Journal of Business Strategy, 11(1), 162-172.

Walsh, J. P. (1995). Managerial and organizational cognition: Notes from a trip down memory lane. Organization Science, 6(3), 280-321. https://doi.org/10.1287/orsc.6.3.280

Weber, E. U., \& Johnson, E. J. (2009). Mindful judgment and decision making. Annual Review of Psychology, 60, 53-85. https://doi.org/10.1146/annurev. psych.60.110707.163633

Wei, Z., Yi, Y. \& Guo, H. (2014). Organizational learning ambidexterity, strategic flexibility, new product development. Journal of Product Innovation Management, 31, 832-847. https://doi.org/10.1111/jpim.12126

Weick, K. E. (1995). Sense making in Organizations. Thousand Oaks, CA: sage Publications.

Wholey, D., \& Brittain J. (1989). Characterizing environment variation. Academy of Management Journal, 32, 867-882. https://doi.org/10.2307/256572

Wright, P. M., \& Snell, S. A. (1998). Toward a unifying framework for exploring fit and flexibility in strategic human resource management. Academy of Management Review, 23, 756-772. https://doi.org/10.5465/amr.1998.1255637

Yan, S., \& Chew, D. A. S. (2011). An investigation of marketing strategy, business environment and performance of construction SMEs in China. African Journal of Business Management, 5(6), 396-2405.

Yu, J., Engleman, R. M., \& Van de Ven, A. H. (2005). The integration iourney: An attention-based view of the merger and acquisition integration process. Organization Studies, 26(10), 1501-1528. https://doi.org/10.1177/0170840605057071

Zahra, S. A., Hayton, J. C., Neubaum, D. O., Dibrell, C., \& Craig, J. (2008). Culture of family commitment and strategic flexibility: the moderating effect of stewardship. Entrepreneurship Theory and Practice, 32, 1035-1054. https://doi.org/ 10.1111\%2 Fj.1540-6520.2008.00271.x

Zammuto, R. F. (1984). A comparison of multiple constituency models of organizational effectiveness. Academy of Management Review, 9(4), 606-616. https://doi.org/10.5465/amr.1984.4277358

Zhang, M. J. (2006). IS support for strategic flexibility, environmental dynamism, and firm performance. Journal of Managerial Issues, 18, 84-103.

\section{Copyrights}

Copyright for this article is retained by the author(s), with first publication rights granted to the journal.

This is an open-access article distributed under the terms and conditions of the Creative Commons Attribution license (http://creativecommons.org/licenses/by/4.0/). 